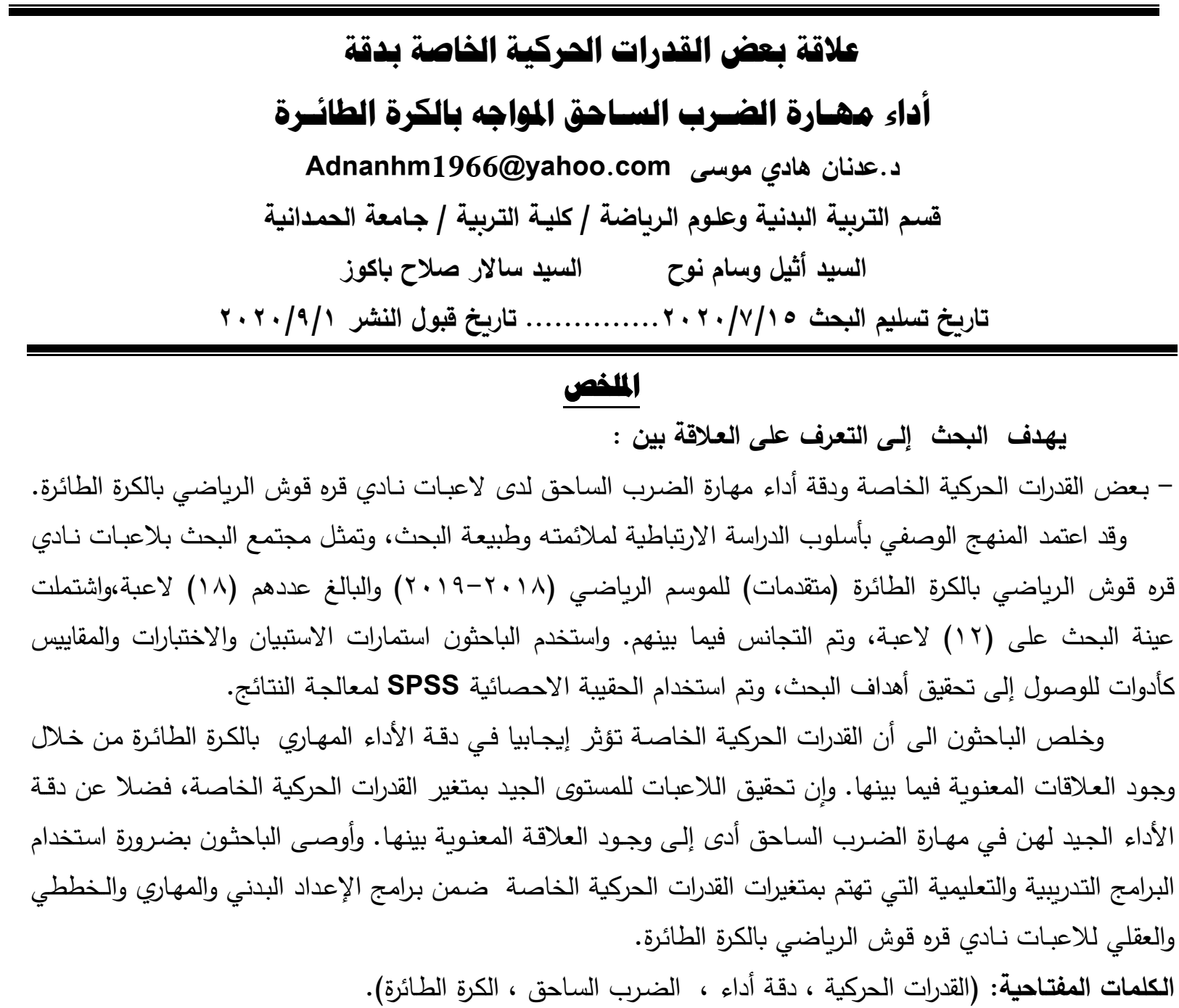

\title{
Relationship of some special kinetic abilities with the performance accuracy of spike skill in volleyball
}

Dr. Adnan Hadi Mousa Adnanhm1966@yahoo.com

Department of Physical Education And Sports Science

College of Education / Al-Hamdaniyah University

Mr. Atheel Wissam Noa

Mr. Salar Salah Bakouz

\section{The research aims to:}

- Knowing the relationship between some special kinetic abilities with the performance accuracy of spike skill for the female players of Qaraqosh Sports Club in volleyball.

The researchers used the descriptive method by correlation study style approach due to its suitability and the nature of the research, and the research community was represented by the female players of Qaraqosh Sports Club in volley ball (advanced) for the sports season (2018-2019) and their number is (18) female players, and the research sample included (12) female players. Homogeneity between them was done, researchers used questionnaire forms tests and measurements as tools to reach achievement of research goals. The SPSS statistical package was used to treat the result.

And the researchers concluded that special kinetic abilities positively affect the accuracy of volleyball's skill performance through the significant relationships between 
علاقة بعض القدرات الحركية الخاصة بدقة أداء مهارة الضرب الساحق المواجه بالكرة الطائرة

them. The achievement of the female players to the good level of the variable of the special kinetic abilities as well as the accuracy of their good performance in the skill of spike led to the significant relationship between them. The researchers recommended the necessity of using training and educational programs that are concerned with the variables of special kinetic abilities within the physical, skill, planning and mental preparation programs for the female players of Qaraqosh Sports Club in volleyball.

Key words: (kinetic abilities, performance accuracy, spike, volleyball) .

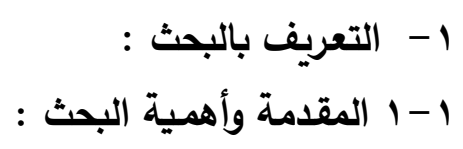

تعد الرياضة المقياس الحقيقي للتقدم في المجتمعات المتحضرة وذلك لما لها من مكانة كبيرة في التقدم الفكري لأي مجتمع، ومن اجل التفوق الرياضي والوصول إلى المستويات المتميزة عالميا، نرى أن الدول المتقدمة لا تدخر وسعا أو بابا في البحث إلا وطرقته عن كل ما هو مبتكر من وسائل علمية تحقق الهدف، لعزئ ولعبة الكرة الطائرة من الألعاب الفرقية التي كونت لنفسها أساليب متقدمة إذا ما قورنت بعدرها القصير نسبياً كونها تعتبر من الألعاب المليئة بالفرص التي تساعد ممارسيها على النمو البدني والحركي والعقلي والانفعالي.

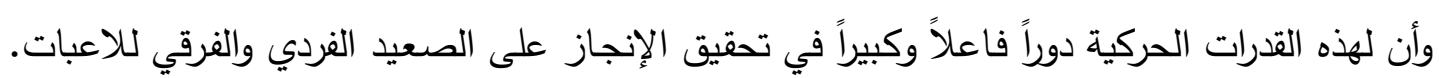

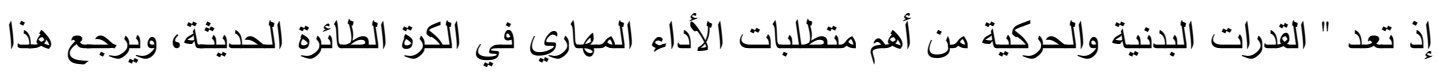
إلى كونها العامل الحاسم في كسب المباريات، وذلك لكون القدرات البدنية والحركية تعد الدعامة الأساسية في أداء مهارات الكرة الطائرة بصورة مناسبة وسليمة ، فلا يمكن الحصول على ضرب هجومي جيد من لاعبة ليس

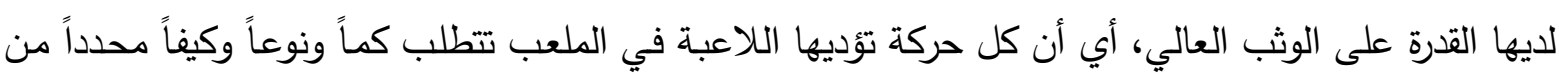

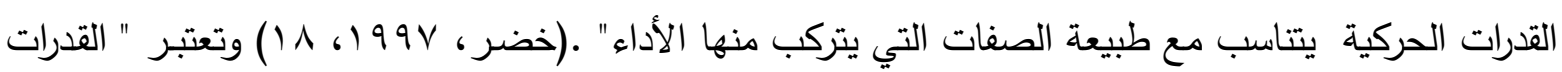
البدنية والحركية هي القاعدة الهامـة التي تستطيع بها اللاعبة التحرك في الملعب بسرعة للوصول إلى الكرة، وتلزم اللاعبة القوة حتى تستطيع الوثب إلى الأعلى لأداء الضربات بقوة كبيرة، كما تحتاج اللاعبة إلى تتمية

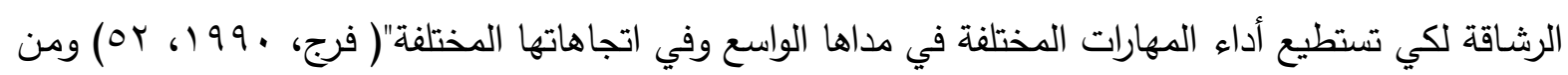
خلال ذلك بدأ التتافس بين دول العالم في ابتكار الأسس العلمية الحديثة بإجراء الدراسات والبحوث التي يمكن من خلالها تطوير مستوى الأداء الفني والبدني والحركي ، وكذلك يتطلب الأداء للقدرات الحركية التي تعد إحدى لبـ لاء

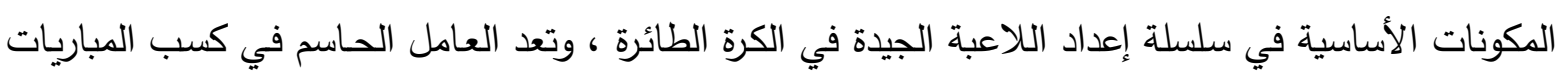

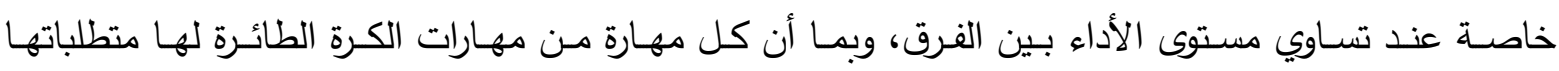
الخاصة من القدرات الحركية كان لزاما على المدربين مراعاة ذلك، واللاعبة التي تتمتع بقدرات حركية عالية

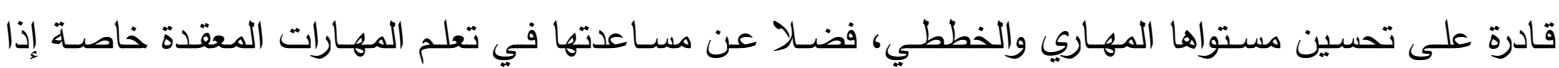
علمنا إن مهارة الضرب الساحق تتطلب قدرات حركية خاصة كي تستطيع اللاعبة تنفيذ الواجب الحركي. لذا فإن أهمية البحث تكمن في التعرف على العلاقة بين بعض القدرات الحركية وتأثيرها على دقة أداء مهارة الضرب الساحق في لعبة الكرة الطائرة و لتسليط الضوه على دور وأهمية القدرات الحركية و وضعها نصب أعين المتخصصين كي يعملوا على تطوير التمارين التي تعمل على تتميتها لدى اللاعبات والي ستؤدي بدورها إلى الارتقاء بمستوى الأداء المهاري لديهم. 
إن لاعبـة الكرة الطائرة لا يمكن إن تحقـق الانجـاز والوصـول الى المستويات العليـا مـا لم تتوفر لديها مواصفات جسمية وبدنية وحركية تتماشى مع متطلبات نوع النشاط الرياضي، و وعليه يتم اختيار اللاعبات بما

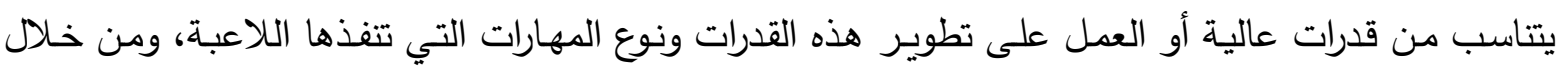

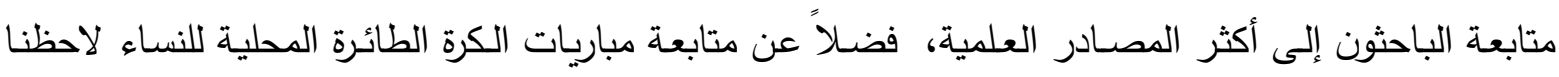
ان هناك تباينـاً في أداء اللاعبـات في أثناء المبـاراة الواحدة، أو في أثنـاء البطـولة وعدم مقدرتهم مـن أداء المهارات الخاصة باللعب بالمستوى نفسه والدقة في أثناء فترة المباراة أو البطولة، مما قد يؤثر في نتائجهم وقد يكون سبب ذلك وجود ضعف وتدني في مستوى بعض القدرات الحركية الخاصـة لدى بعض اللاعبات، وقلة الاهتمام بها من قبل بعض المدربين في العملية التدريبية، علمـا أنها من المتطلبات الأسـاسية للاعبـة الكرة الطائرة.

ولهذا حدد الباحثون هذه المشكلة وأبعادها من خلال إيجاد علاقة هذه القدرات الحركية بدقة أداء مهارة الضرب الساحق في لعبة الكرة الطائرة والوقوف على معالجات هذه المشكلة من اجل الإسهام في الارتقاء بمستوى هذه القدرات لدى لاعبات الكرة الطائرة ومساعدة المدربين للنهوض بمستوى اللعبة. وتتلخص الإه مشكلة البحث بالتساؤل الآتي: هل توجد علاقة بين بعض القدرات الحركية الخاصة بدقة أداء مهارة الضرب السـاحق المواجه لاى لاعبات

- التعرف على العلاقة بين بعض القدرات الحركية الخاصة ودقة أداء مهارة الضرب الساحق المواجه لدى لاعبات نـادي قره قوش الرياضي بالكرة الطائرة.

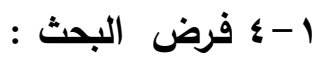
- توجد علاقة معنوية بين بعض القدرات الحركية الخاصة ودقة أداء مهارة الضرب الساحق المواجه لدى لاعبات نادي قره قوش الرياضي بالكرة الطائرة .

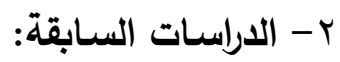

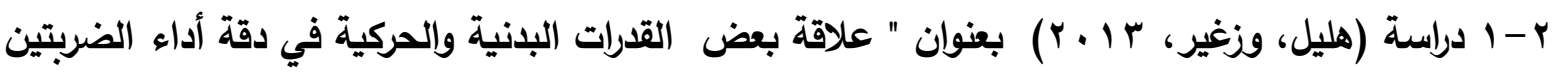

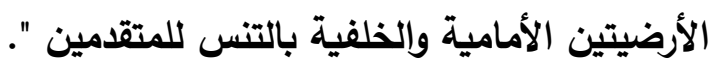
" هدف البحث إلى التعرف على بعض القدرات البدنية والحركية الخاصة لإى لاعبي المنتخب الوطني بالتنس والتعرف على العلاقة بين بعض القدرات البدنية والحركية بدقة أداء الضربتين الأرضيتين الأمامية والخلفية لدى لاعبي المنتخب الوطني بالتنس، وافترض الباحثان بان هناك علاقة ارتباط ذات دلالة إحصائية

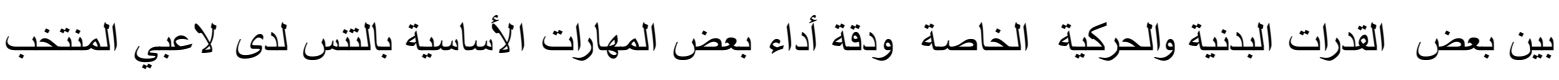
الوطني. وتطرق الباحثان إلى الدراسات النظرية التي احتوت على مباحث متعددة تتعلق بموضوع البحث ، وقد

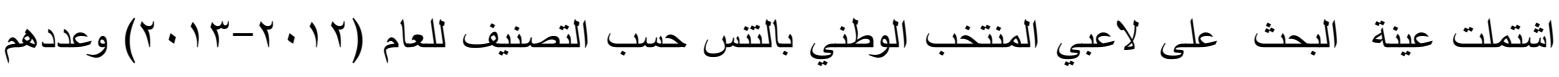

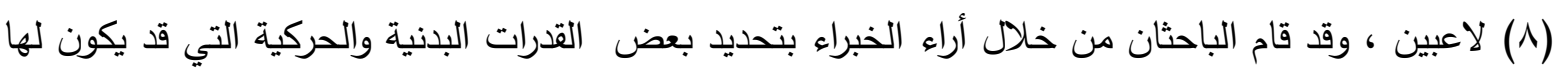




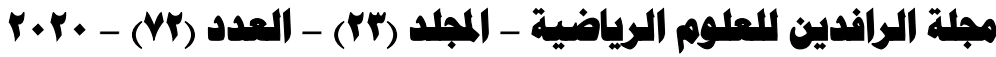

علاقة بعض القدرات الحركية الخاصة بدقة أداء مهارة الضرب الساحق المواجه بالكرة الطائرة

علاقة بلعبة التتس وكذلك تم اختيار الاختبارات الخاصة بهذه القدرات البدنية والحركية، وكذلك الاختبارات الخاصة بمهارتي الضربتين الأمامية والخلفية وبعد إجراء التجربة الاستطلاعية قام الباحثان بعمل الاختبارات الأساسية للبحث حيث تم إجراء اختبار الضربتين الأمامية والخلفية للاعبي المنتخب، وفي اليوم التالي تم إجراء الاختبارات البدنية والحركية وعلى الملاعب الخارجية نفها، وبعد جمع البيانات ومعالجتها إحصائيا توصل الباحثان إلى ما يأتي : البـ ا- وجود ارتباط معنوي بين القدرات البدنية والحركية (القوة المميزة بالسرعة للذراعين ، والاستجابة الحركية،

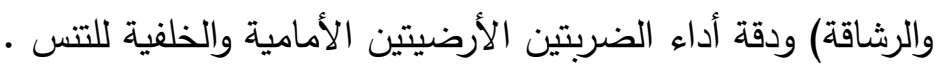
ץ- وجود ارتباط غير معنوي بين القوة المميزة بالسرعة للرجلين ودقة أداء الضربتين الأرضيتين الأمامية

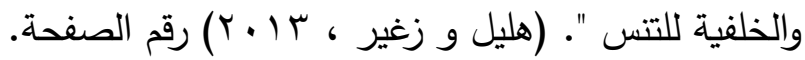

r-1 منه- البحث

استخدم الباحثون المنهج الوصفي بأسلوب الدراسة الارتباطية.

r-r مجتمع البحث وعينته

تمثل مجتمع البحث بلاعبات نـادي قره قوش الرياضي بالكرة الطائرة (متقدمات) للموسم الرياضي (1 ( • ؟9 ( • Y) والبالغ عددهم (1) (1) لاعبة، وقد اختيرت عينة البحث بطريقة عمدية " إذ إن الباحث يختار العينة

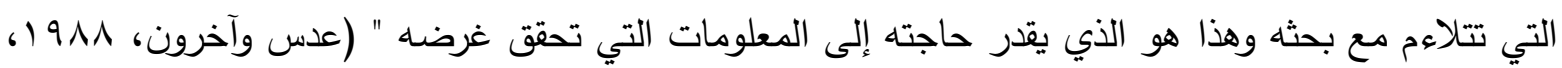

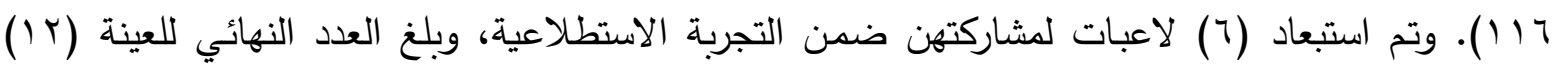
لاعبة ويمثلون نسبة (7 آ.77٪). ولغرض تحقيق التجانس بين اللاعبات تم ضبط المتغيرات آلاتية والجدول ( ) يبين ذلك.

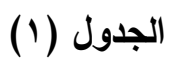

يبين الأوساط الحسابية والانحرافات المعيارية ومعاملات الالتواء لعينة البحث

\begin{tabular}{|c|c|c|c|}
\hline معـامل الالتواء & الانحراف المعياري & وسط ألحسابي & \\
\hline • & Y.VVq & r Y.O. & العمر الزمني (سنة) \\
\hline$\cdot, \vee q 4$ & $\varepsilon . Y . q$ & M & الطول (سم) \\
\hline$\cdot, \varepsilon Y .-$ & r. IVo & 08.917 & الكتلة (كغم) \\
\hline $.197-$ & $1, \wedge \wedge r$ & $7.0 \ldots$ & العمر التدرببي (سنة) \\
\hline
\end{tabular}

ب-

نظرا لشمول الدراسـة على متغيرات القدرات الحركية الخاصـة ومهارة الضرب السـاحق بالكرة الطائرة

تطلب استخدام الأدوات آلاتية : (استمارات الاستبيان ، الاختبارات ، ألمصـادر والمراجع). r-r-1 استمـارات الاستبيان: لتحديد متغيرات الدراسة قام الباحثون بإعداد استمارة استبيان وكما يأتي :

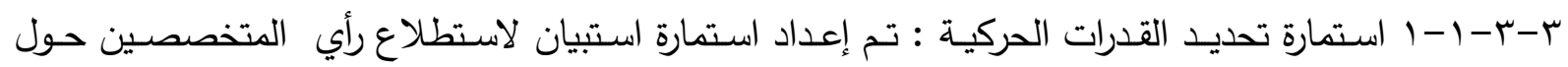
تحديد القدرات الحركية الخاصة . 


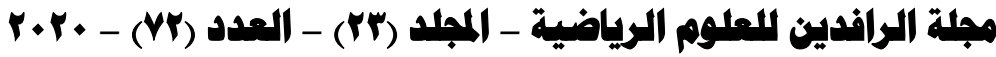

علاقة بعض القدرات الحركية الخاصة بدقة أداء مهارة الضرب الساحق المواجه بالكرة الطائرة

فقد تم عرض الاستمارة على مجموعة من المتخصصين " ضمن مجالات (الكرة الطائرة ، والتعلم

الحركي، والاختبارات والقياس ). لبيان أي القدرات تلائم عينة البحث، وبعد جمع الاستمارات وتفريغها تم تحديد

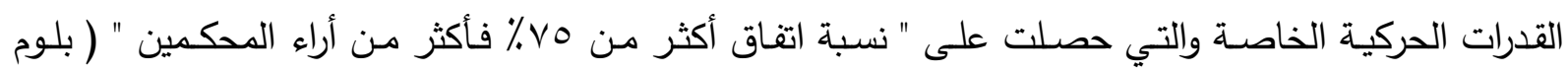

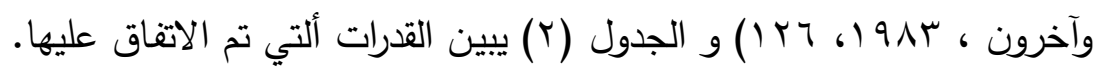

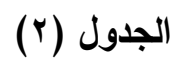

يبين نسبة اتفاق المتخصصين حول تحديد أهم القدرات الحركية بالكرة لطائرة

\begin{tabular}{|c|c|c|c|c|}
\hline \multirow{2}{*}{ نسبة الاتفاق } & \multicolumn{2}{|c|}{ عدد المتخصصين } & \multirow{2}{*}{ القدرات الحركية } & \multirow{2}{*}{$ت$} \\
\hline & ألمتفقين & ألكلي & & \\
\hline$\% 1 \ldots$ & $v$ & $v$ & سرعة رد الفعل & -1 \\
\hline$\% 1 \ldots$ & $\checkmark$ & v & الرشاقة & $-r$ \\
\hline$\% \wedge \bullet . \vee 1 \leq$ & 7 & v & المرونة & $-r$ \\
\hline
\end{tabular}

r-r- - - - استمارة تحديد اختبارات القدرات الحركيـة : تم إعداد استمارة استبيان لاستطلاع المتخصصين حول تحديد الاختبارات التي تقيس هذه القدرات وكما في الملحق (1) ، فقد تم عرض الاستمارة على مجموعة من المتخصصين * وبعد جمـع الاستمارات وتفريغها اتفق المختصـون على تحديد الاختبارات المختارة لعينـة البحث وبنسبة اتفاق (vo\%) فأكثر . والجدول (r) يبين ذلك.

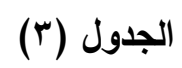

يبين نسبة اتفاق المتخصصين حول تحديد اختبارات القدرات الحركية

\begin{tabular}{|c|c|c|c|c|}
\hline عدد المتخصصين & نسبة الاتفاق & اختبارات القدرات الحركية & القدرات الحركية & $ت$ \\
\hline 7 & 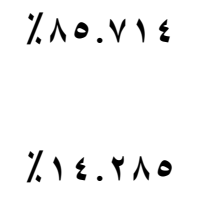 & - اختبار القدرة على الاستجابة الحركية والتحرك & سرعة رد الفعل & 1 \\
\hline 9 & $\begin{array}{l}\% \wedge \bullet . \vee 1 \leq \\
\% \wedge \leq . \wedge \wedge 0\end{array}$ & 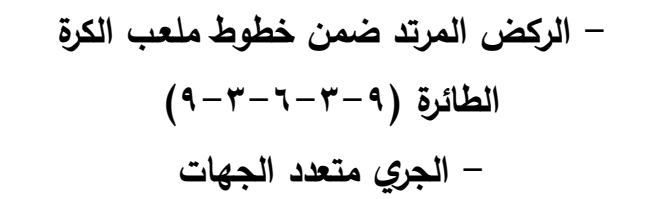 & الرشاقة & r \\
\hline 1 & $\begin{array}{l}\% 1 \leq .4 \wedge 0 \\
\% \wedge 0 . \vee 1 \leq\end{array}$ & - اختبار رفع الكتفين لأعلى من وضع الجذع من الوقوف الانبطاح - اختبار & المرونة & $r$ \\
\hline
\end{tabular}

" أسماء المتخصصين كما موضحة في الملحق (r).

" أسماء المتخصصين كما موضحة في الملحق (r). 
r-r-1-r اسـتمارة تحديد اختبـار مهـارة الضـرب السـاحق : فقد تم إعداد استبيان لاستطلاع أراء

المتخصصين حول تحديد أهم اختبار يقيس مهارة الضرب الساحق وكما في الملحق ( (1). تم عرض الاستمارة على مجموعة من المتخصصين * ضـمن مجـالات (التعلم الحركي ، والاختبارات

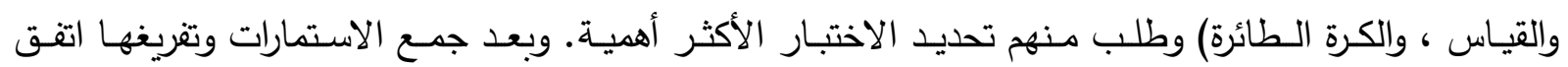

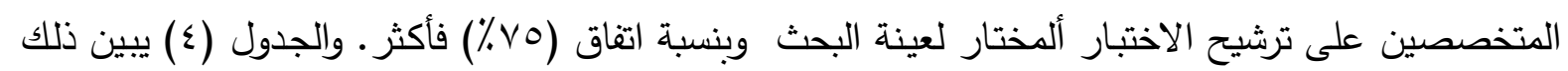

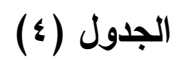

يبين نسبة اتفاق أراء المتخصصين حول أهم اختبار مهاري للضرب الساحق

\begin{tabular}{|c|c|c|c|c|}
\hline ألمختصين & نسبة الاتفاق & الاختبارات & المهارات الأسـاسية & ت \\
\hline $\begin{array}{l}7 \\
1\end{array}$ & $\begin{array}{l}\% \wedge \bullet . \vee 1 \leq \\
\% \wedge \leq . \times \wedge 0\end{array}$ & 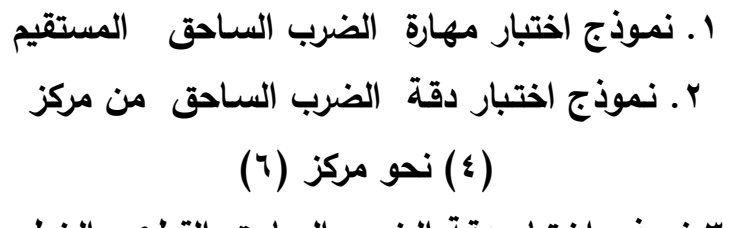 & الضرب السـاحق & .1 \\
\hline- & $\% \ldots$ & r.نموذج اختبار دقة الضرب السـاحق القطري والخطي & & \\
\hline
\end{tabular}

r-r

r-r-r r-r-r - 1 - 1 " اختبار القدرة على الاستجابة الحركية والتحرك بسرعة وفقا لاختيار المثير"

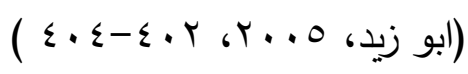

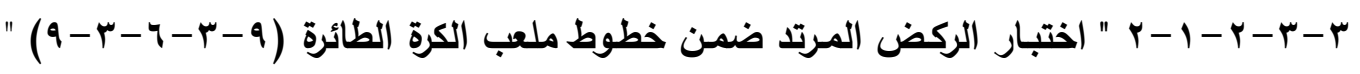

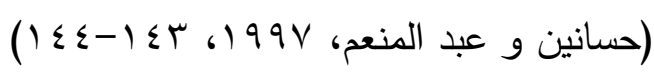

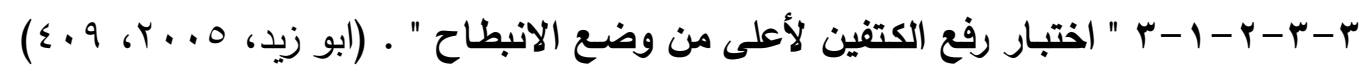
rالملحق (1) يوضح مواصفات اختبارات القدرات الحركية

r-r-r-r-r والملحق (r) يوضح مواصفات الاختبار المهاري لعينة البحث. r- الأجهزة والأدوات المستخدمة 1. ميزان طبي يقيس لأقرب نصف كيلو غرام، صافرة ، طباشير، مسطرة. r. . ساعة إيقاف الكترونية نوع (Casio) لقياس الزمن بالدقائق والثواني. r. شريط قياس لقياس المسافات + شريط لاصق بعرض (مسم). ؛. ملعب الكرة الطائرة قانوني + شبكة كرة الطائرة + كرات طائرة عدد (· ل (1).

" اسماء المتخصصين في الملحق (ץ). 


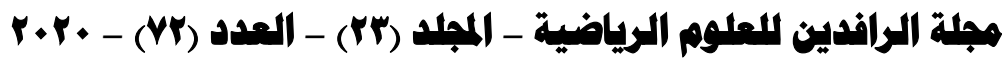

علاقة بعض القدرات الحركية الخاصة بدقة أداء مهارة الضرب الساحق المواجه بالكرة الطائرة

ب-ه ألاراسـة ألاستطلاعية :

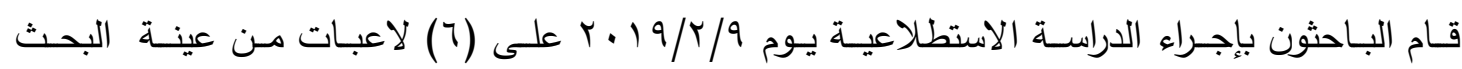
الأصلية. وقد كان من نتائج الدراسة الاستطلاعية تحقيق الأهداف المرجوة وتكوين صورة واضحة لإى لإس الباحثون

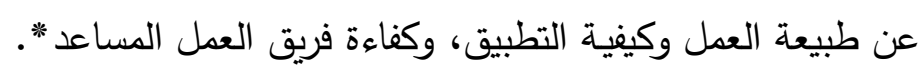

r-

تم تطبيق اختبارات القدرات الحركية والاختبار المهاري على جميع لاعبـات نـادي قره قوش الرياضي

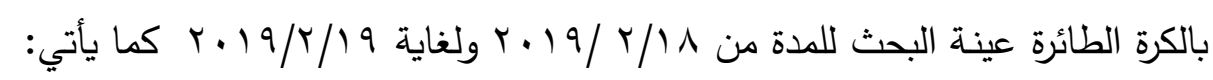

ا. ـ تم إجراء اختبار القدرات الحركية والاختبار المهاري تحت الظروف نفسها لعينة البحث ، وتم استخدام أجهزة قياس واحدة. r. تسجيل النتائج طبقاً للمواصفات والثروط المحددة لكل اختبار . r. قسم الباحثون تطبيق القياسـات والاختبارات المعتمدة في البحث على مدى يومين لعينـة البحث وكما يلي:

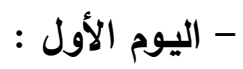

قياس الطول والكتلة، وتطبيق اختبارات القدرات الحركية الخاصة بعد أن تم عرض وشرح جميع مفردات الاختبارات.

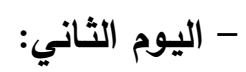

تطبيق الاختبار الـمهاري بعد أن تـم شـرح كيفيـة تتفيذ الاختبـار والتـأكد مـن مدى استيعاب اللاعبات لطريقة التتفيذ، إذ تأخذ اللاعبة الإحماء الكافي ثم تقوم بتطبيق اختبار مهارة الضرب الساحق بالكرة الطائرة . : الوسائل الإحصائية للتوصـل إلـى نتـائج البحـث قـام البـاحثون بمعالجـة البيانـات إحصــائيا باسـتخدام برنـامج الحقيبـة الإحصائية للعلوم الاجتماعية (SPSS).

\begin{tabular}{|c|c|}
\hline & " تكون فريق العمل المساعد من : \\
\hline مدرب نادي قرقوش الرياضي للنس & 1. السيد سعد بهنام جرجيس \\
\hline مدر & r. السيد مارفن سعد بهنـــان \\
\hline
\end{tabular}


علاقة بعض القدرات الحركية الخاصة بدقة أداء مهارة الضرب الساحق المواجه بالكرة الطائرة

$$
\text { צ - - عرض النتائج ومنـاقشتها: }
$$

سيتم عرض النتائج ومناقثتها في ضوء البيانات الإحصائية التي تم الحصول عليها من عينة البحث

$$
\text { وعلى النحو آلاتي : }
$$

ا ـ قياس متغيرات القدرات الحركية والجدول (0) يبين ذلك.

\begin{tabular}{|c|c|c|c|c|}
\hline الانحراف & الحسابي & القياس & اختبارات تركيز الانتباه و القدرات البدنية وإلصركية & متغيرات \\
\hline .1107 & $1 . \wedge \vee \cdot$ & ثا & اختبار القدرة على الاستجابة الحركية والتحرك & \multirow{3}{*}{ القدرات } \\
\hline .rmat & ヘ.V7 & ثا & الركض المرتد (q-r-q-r-q) & \\
\hline $0 .\{\wedge r V$ & TV.rTh & سم & اختبار رفع الكتفين لأعلى من وضع الانبطاح & \\
\hline
\end{tabular}

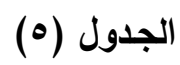

يبين الأوسـاط الحسابية والانحرافات المعيارية لعينة البحث في اختبارات القدرات الحركية

يتبين مـن الجدول أعـلاه الأوسـاط الحسـابية والانحرافات المعيـارية لمتغيرات القدرات الحركية التي تم قياسها من خلال الاختبارات المستخدمة. r. قياس دقة أداء مهارة الضـرب السـاحق المعتمد في البحث على لاعبـات نـادي قره قوش الرياضي بالكرة الطائرة، والجدول (؟) يبين ذلك.

\begin{tabular}{|c|c|c|c|c|}
\hline الانحراف & الوسطابي & وحدة القياس & المعالجات الإحصائية & \\
\hline $1 . V \bullet \wedge 1$ & $10 \ldots$ & درجة & اختبار مهارة الضرب ألسـاحق & دقة الأداء \\
\hline
\end{tabular}

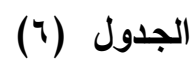

يبين الأوسـاط الحسابية والانحرافات المعيارية لاختبار مهارة الضرب ألساحق بألكرة ألطائرة

يتبين من الجدول أعلاه ألوسط الحسابي والاتحراف المعياري لدقة أداء مهارة الضرب ألسـاحق بالكرة الطائرة ، والتي تم قياسها من خلال الاختبار ألمستخدم.

ولأجل تحقيق فرضية البحث: تم حساب معامل الارتباط بين كل متغيرات القدرات الحركية التي تم قياسها مع دقة أداء مهارة الضرب ألساحق بالكرة الطائرة لدى اللاعبات وعلى النحو آلاتي: 
علاقة بعض القدرات الحركية الخاصة بدقة أداء مهارة الضرب السـاحق المواجه بالكرة الطائرة

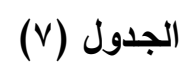

يبين معاملات الارتباط بين متغيرات القدرات الحركية ودقة الأداء المهاري

\begin{tabular}{|c|c|}
\hline دقة الأداء & \\
\hline مهارة الضرب & القدرات الحركية \\
\hline$* .94 q-$ & - اختبار القدرة على الاستجابة الحركية وإلتحرك بسرعة وفقا لاختيار المثير \\
\hline *..งฯนー & - اختبار الركض المرتد (q-r-q-r-q) \\
\hline$* . .9 .0$ & - اختبار رفع أكتفين لأعلى من وضع الانبطاح \\
\hline
\end{tabular}

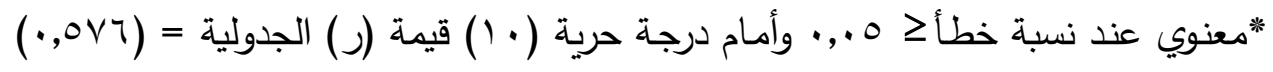
ع - r مناقشة النتائج

يثبت الجدول (V) وجود عـلاقة معنوية بين متغيرات القدرات الحركية ودقة الأداء المهاري، وذلك مـا يؤكد هذا الارتباط المهم لأنه يعبر عن حالة مهمة من حالات التوافق البدني المهاري الذي يمكن من خلاله أن

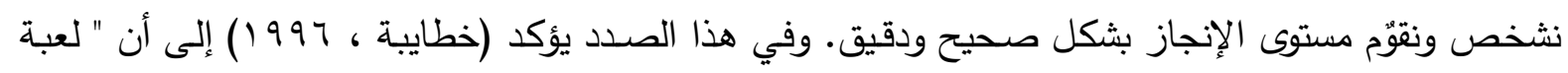

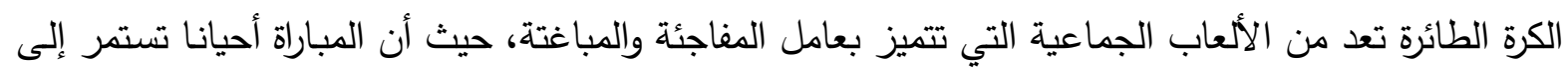
اكثر من ساعتين فهذا يحتاج من اللاعبين قدرة عالية من التركيز ويقظة مستمرة وتركيز دائم حتى يستطيعوا التغلب على المواقف المفاجئسة والصـوبات الغير متوقعـة والعهل لصـالح فريقهم في كسب نقطـة المبـاراة أو

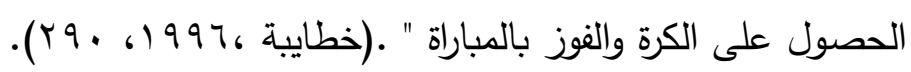
لذلك يرى الباحثون أن الدقة تعد من أهم القدرات الحركية التي تحتاجها لاعبـة الكرة الطائرة في تتفيذها

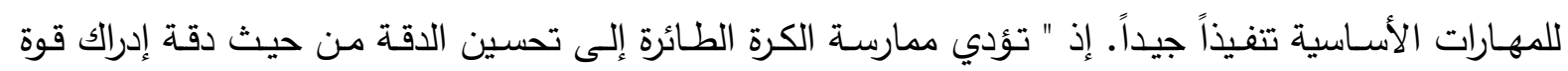
الضربات وسرعتها ودقة إدراك وارتفاع الكرة وبعدها واتجاهها ومكان مناسب لتوجيهها إليه سواء كان ذلك في تلي

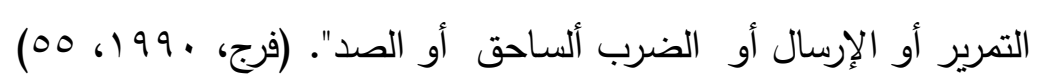

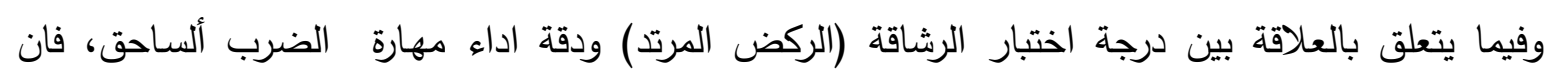
الجدول المرقم (V) يبين وجود علاقة معنوية عكسية بين هذه المتغيرات ويعزو الباحثون هذه النتيجة إلى أن " لئل الرشاقة تحتل المرتبة الأولى للقدرات الحركية في رياضة الكرة الطائرة لما لها من أثر ناجح على دقة الضردية الساحقة، حيث تتطلب هذه المهارة تغير اتجاه الجسم أثناء الطيران في الهواء بسرعة فائقة ".

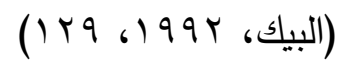

ويضيف (عبد الكريم، ( . . r) أن" الضربة الساحقة تظهر فيها أهمية الرشاقة من تغيير الاتجاه مع دمج عدة

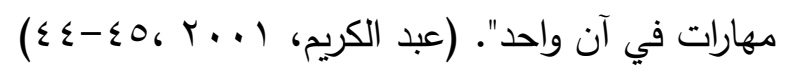


ويرى الباحثون أن الرشاقة تعد من أهم القدرات التي تكسب الرياضي القدرة على الأداء الحركي في

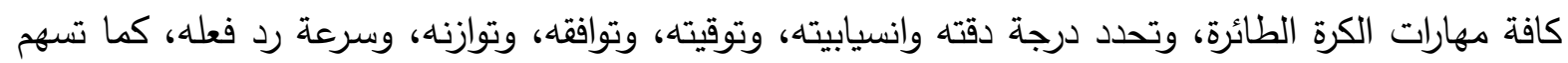

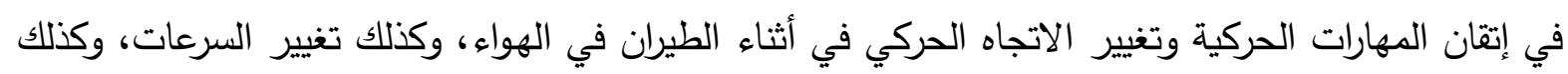

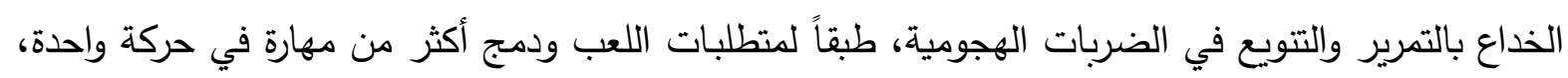

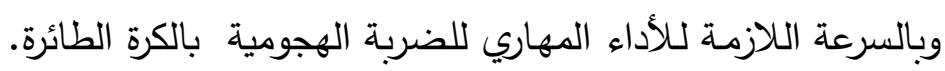

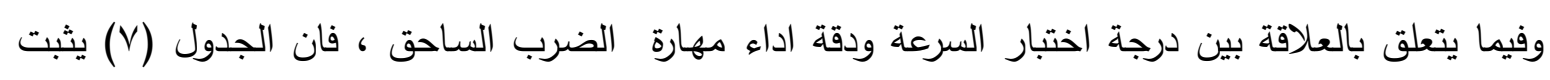

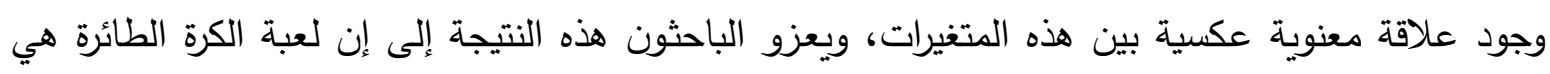

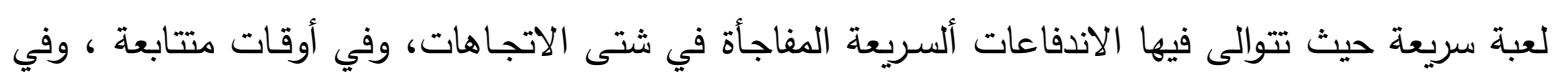
مسافات قصيرة متكررة خلال المباراة .

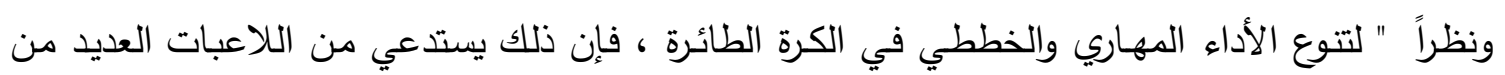

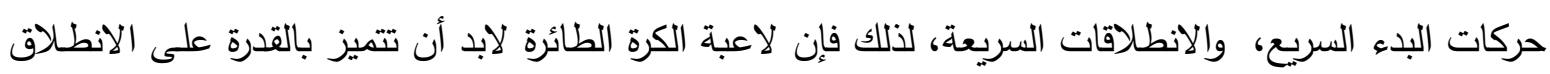

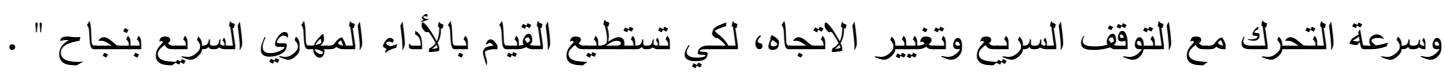

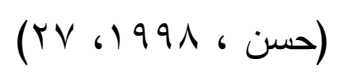

ويرى الباحثون أن السرعة عبارة عن سرعة الانقباضات ألعضلية، ولها علاقة بالسرعة الحركية، فهي تتقسم التحا

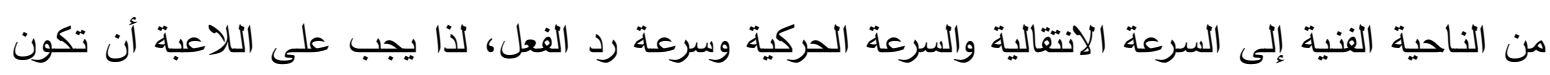

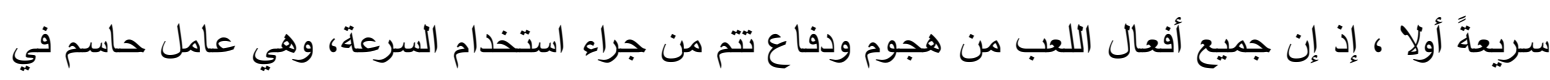

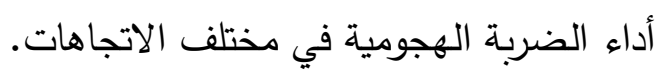

وفيما يتعلق بالعلاقة بين درجة اختبار المرونة ودقة اداء مهارة الضرب ألساحق، فان الجدول المرقم (V)

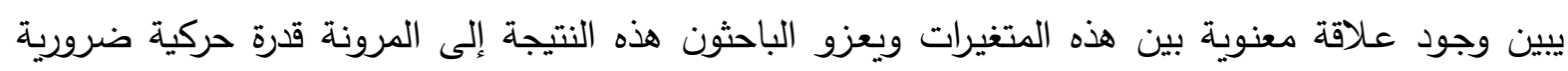

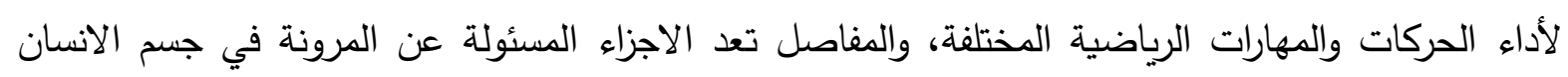

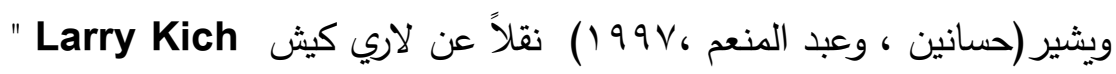

ان اهمية ومضمون المرونة في الكرة الطائرة تتمثل في : 1- ان قابلية العضلات والاربطة للامتطاط. r- قابلية المفاصل للحركة (المرونة الدفصلية).

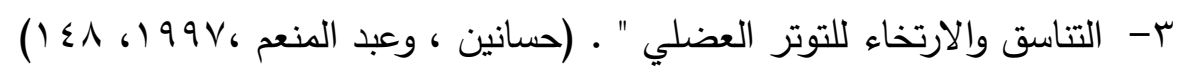
وقد اتقق العديد من العلماء على ان المرونة احدى القدرات الضرورية في الكرة الطائرة. 
علاقة بعض القدرات الحركية الخاصة بدقة أداء مهارة الضرب الساحق المواجه بالكرة الطائرة

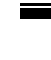

$$
\begin{array}{r}
\text { - - الاستتتاجات والتوصيات } \\
\text { - الاستنتاجات }
\end{array}
$$

0-1-1 ت تؤثر القدرات الحركية إيجابيا في دقـة الأداء المهاري بالكرة الطائرة، من خـلال وجود العلاقات

المعنويـة فيما بينها .

ه- - إن إن تحقيق لاعبات نـادي قره قوش الرياضي بالكرة الطائرة للمستوى ألجيد بمتغير القدرات الحركية

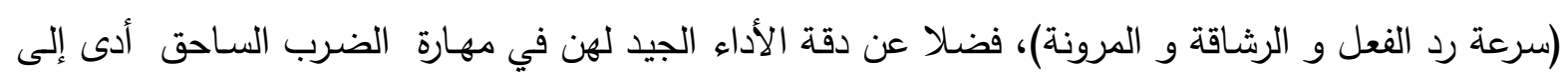

وجود العلاقة المعنوية بينها.

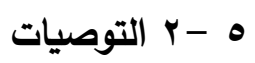

ه-r-1 استخدام البرامج التدريبية والتعليمية التي تهتم بمتغيرات القدرات الحركية ضـمن برامج الإعداد

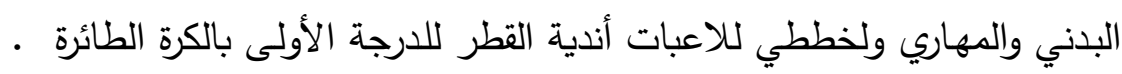

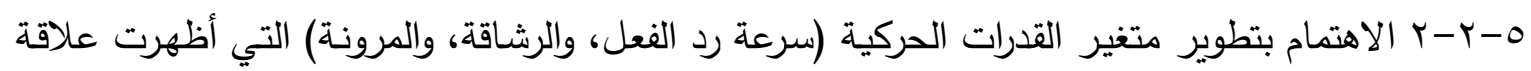

معنوية ودقة أداء مهارة الضرب الساحق في الكرة الطائرة للاعبات نـادي قره قوش الرياضي بالكرة الطائرة.

צ- المصادر العربية والأجنبية :

ا ـ أبو زيد، عماد الدين (0 . r): التخطيط والأسس العلمية لبناء وأعداد الفريق في الالعاب الجماعية،

طا، منشأة المعارف الاسكندرية.

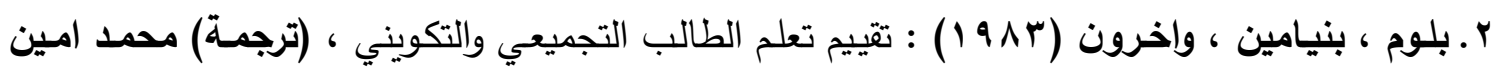

المفتي واخرون ، ماكروهيل ، القاهرة.

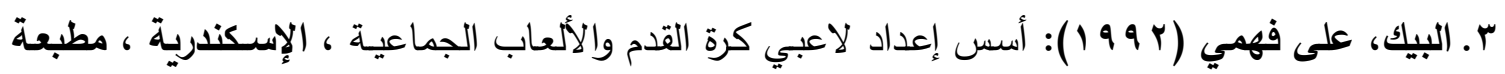

التوني بالإسكندرية.

ع ـ التكريتي، وديـع ياسـين محمد و العبيدي ، حسن محمد عبد (999 (19): التطبيقات الإحصـائية في

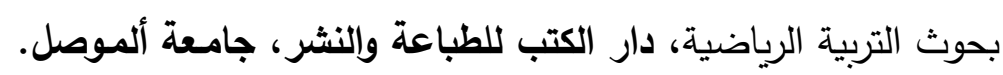

ه. حجاج، حسين (999 190) : دلالة مساهمة بعض الصفات البدنية في مستوى الاداء المهاري للمبارزات

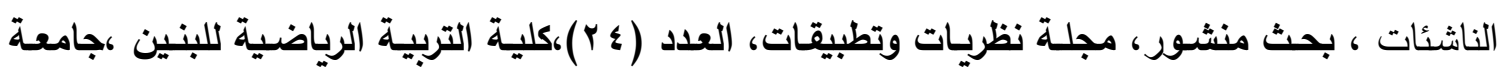
الإسكندرية.

צ. حسـانين، محمد صبحي وعبد المنعم حمدي (9 9 V ( )): الأسس العلمية للكرة الطائرة وطرق القياس والتقويم، طا، مركز الكتاب للنشر، القاهرة.

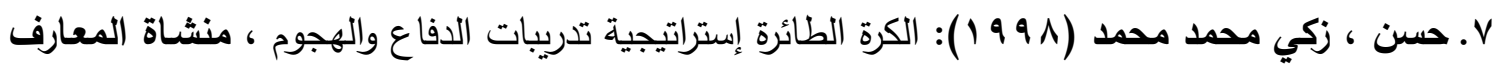

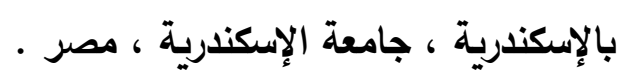

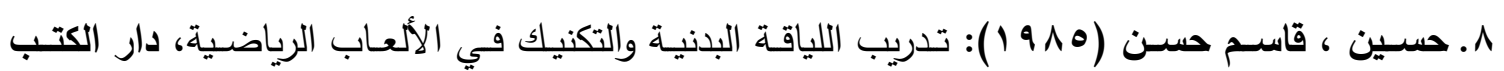

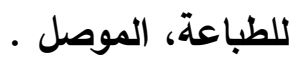




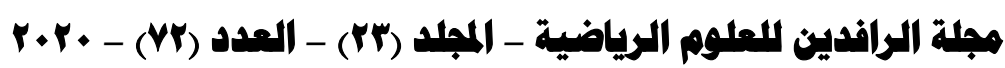

علاقة بعض القدرات الحركية الخاصة بدقة أداء مهارة الضرب السـاحق المواجه بالكرة الطائرة

9 ـ خضـر، حنـان (99v ( )): تأثير التـدريب الفتري منخفض الثدة على تحسين بعض القدرات الحركية

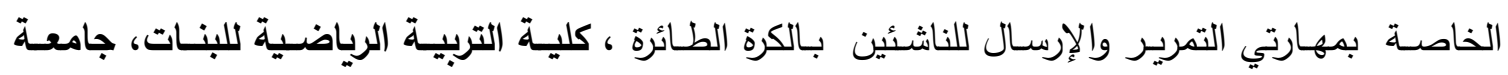

الإسكندرية.ة.

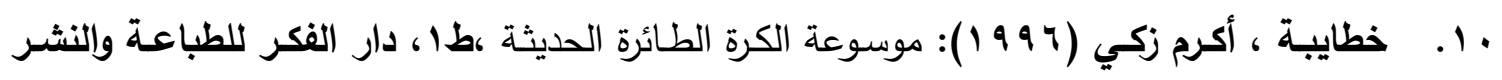
والتوزيع ، عمان ، الأردن.

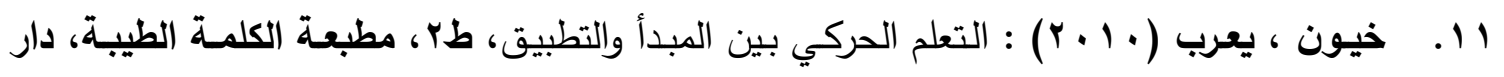

الكتب والوثائق، بغداد، العراق.

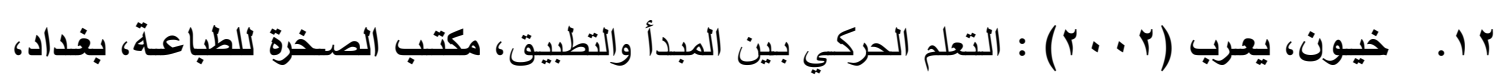
العراق.

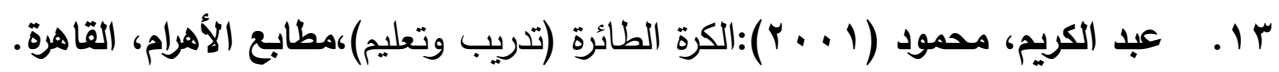

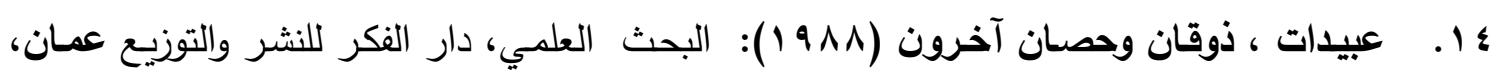
الأردن.

ه ا . عدس ، عبد الرحمن وآخرون (9^^ (1)): دليل المعلم في بنـاء الاختبارات التحصيلية، المنظمـة العربية للتربية والثقافة والعلوم ، تونس.

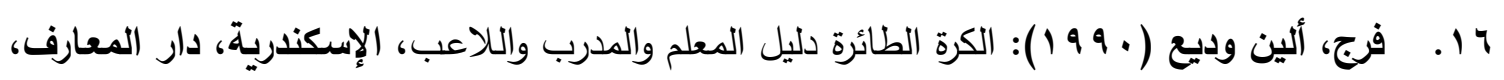

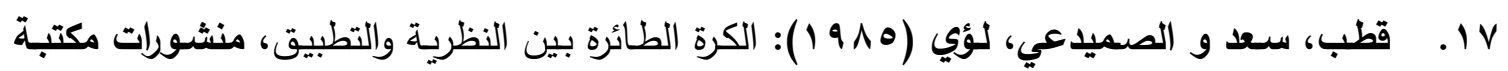
بسام، الموصل.

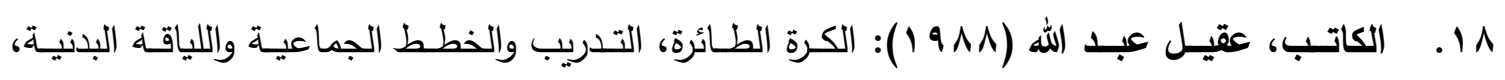
Volleyball

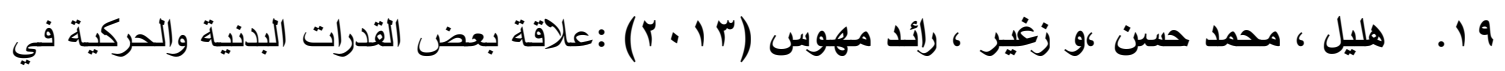

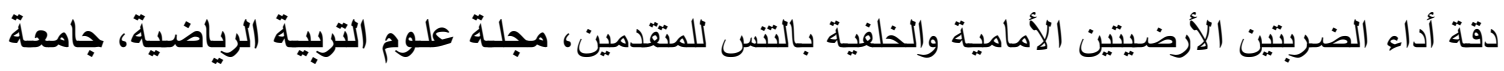

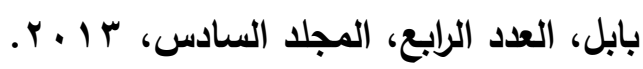

20 . Marion Y.L.A Lecenders; Akineiological Analvis of the spike volleyball Technical ; Jowal ,NO , November ,1980,P25.

21.. Ralph \& Bob B. (1982): Spiking Champion Ship Volleyball by The Experts 2nd ed., Leisure Pre, West point, Network. 
علاقة بعض القدرات الحركية الخاصة بدقة أداء مهارة الضرب الساحق المواجه بالكرة الطائرة

\section{الملدق (1)}

يوضتح مواصفات اختبارات القدرات الحركية

الاختبار الأول

اختبار نيلسون للاستجابة الحركية الانتقائية

• الغرض من الاختبار : قياس القدرة على الاستجابة و التحرك بسرعة و دقة على الآلى وفق الاختبار و المثير •

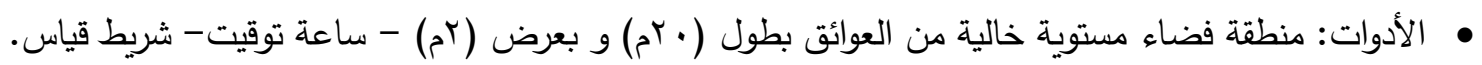

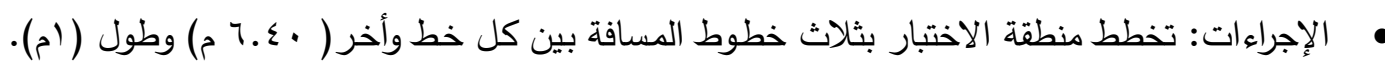

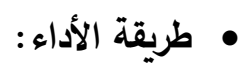

• تقف ألمختبرة عند احدى نهايتي خط المنتصف في مراجعة الحكم الذي يقف عند نهاية الطرف الاخر للخط.

• تخذ ألمختبرة وضح الاستعداد بحيث يكون خط المنتصف بين القدمين و الجسم ينحني للأمام قليلا.

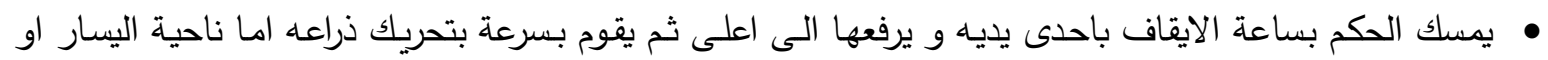
اليمين و في الوقت نفسه يقوم بتشغيل الساعة.

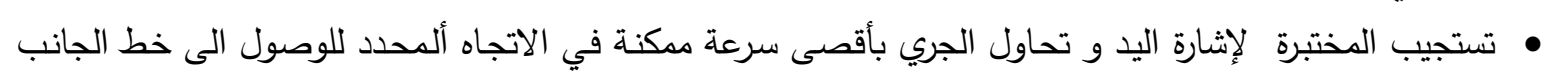

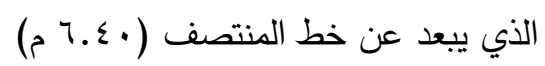

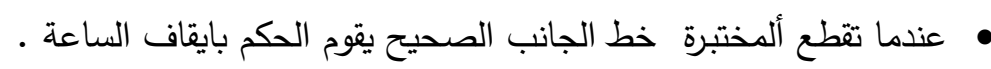
• اذا بدأت ألمختبرة الجري في الاتجاه الخـاطى فـان الحكم يستمر في تشغيل السـاعة حتى تغيير المختبرة من إتجاهها الخاطئ و تصل إلى خط الجانب الاخر . • تعطى ألمختبرة عشرة محاولات متتالية بين محاولة وأخرى (· r ثا) وبواقع خمس محاولات لكل جانب. • يتم اختيار كل جانب بطريقة عشوائية متعاقبه ولتحقيق ذلك تعد عشر قطع من ألورق المقوى (الكارتون) موحدة

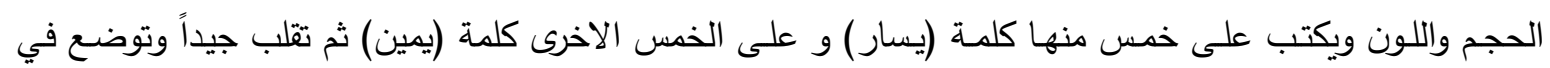
كيس ثم تسحب دون النظر اليها. • يجب التتبــه على ألمختبرة بـأن عدد ألمحساولات ألتـي سـؤديها ليست موزعـة على الاتجاهين بالتساوي، وإنما يحتمل أن يكون عدد المحاولات يتم بطريقة عشوائية وهو يختلف من مختبرة لأخرى.

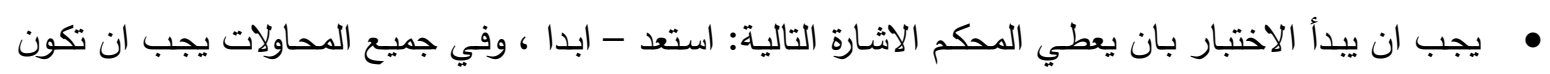

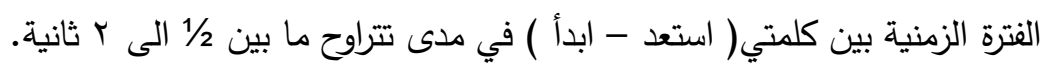
• يجب على المختبر القيام ببعض التمرينات للإحماء.$$
\text { • حساب الدرجات : }
$$

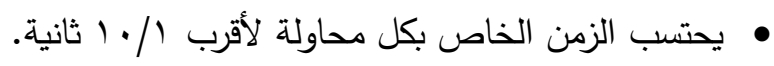

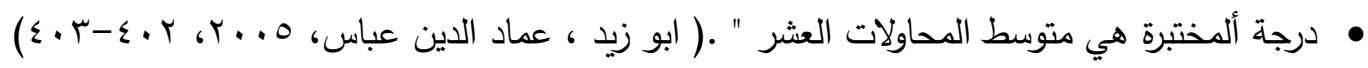




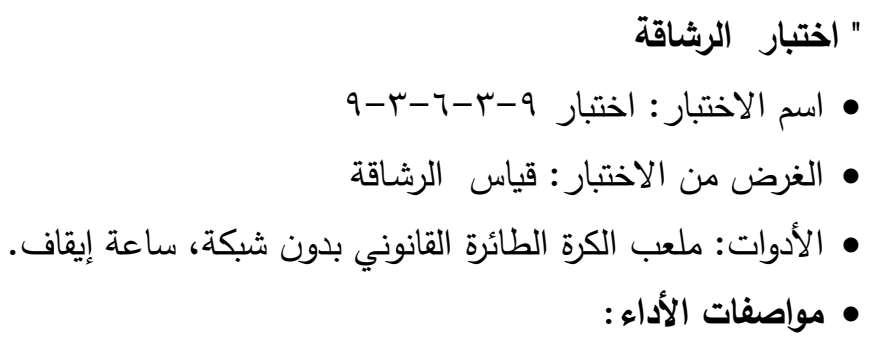

تقف المختبرة خلف خط البداية للملعب ، وعند سماع إثارة البدء تقوم بالجري في اتجاه مستقيم لتلمس خط المنتصف

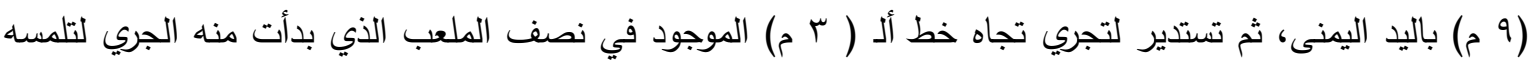

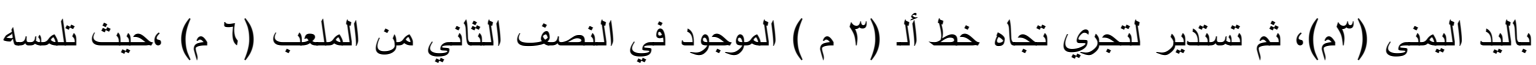

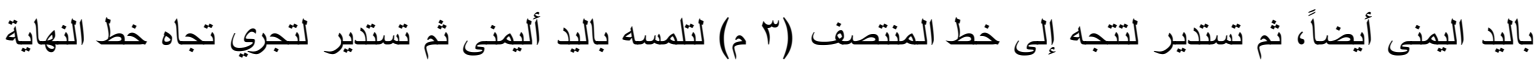
(9 م)، لتجاوزه بكلتا القدمين.

1 - يجب إتباع خط السير -

ץ- إذا أخطأت المختبرة في خط السير يعاد الاختبار بعد أن تحصل على الراحة الكافية. r- يجب لمس الخطوط في كل مرة باليد اليمنى، كما يجب تجاوز خط النهاية بكلتا القدمين. • التسجيل: تسجل للمختبرة الزمن التي قطعت فيه المسافة المحددة وفقاً لخط السير الموضوع ابتداءً من إعلان البداء لئه

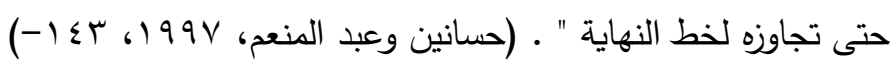
الاختبار الثالث

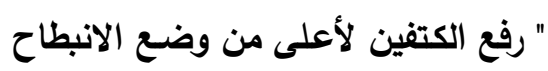
• أسم الاختبار : رفع الكتفين • غرض الاختبار : قياس القدرة على رفع الكتفين لأعلى من وضع الانبن الانباح. •

قائم مقسم إلى وحدات كل منها (1 سم) ويثبت عمودياً على الأرض مع مراعاة بداية الترقيم من أسفل القائم ويلحق بالقائم عارضة صغيرة موازية للأرض ويسهل تحريكها لأعلى ولأسفل. • طريقة الأداء:

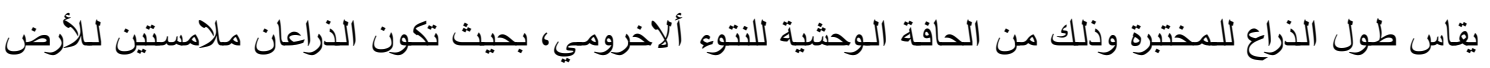
والقائم في أثناء قيام المختبرة بالقبض عليه، بحيث تكون الذراعان ملامستين للأرض والقائم ملامس للأرض أمسام المختبرة ويلاحظ أن يكون امتداد الذراعين بأتساع الكتثين. تتخذ ألمختبرة وضـع الانبطاح على ألأرض مع مد الذراعين بأتساع الكتفين وتقبض المختبرة على ألقائم وتقوم برفعها

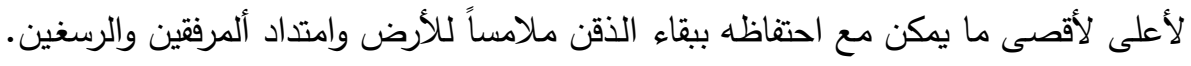

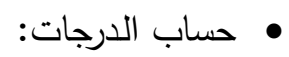

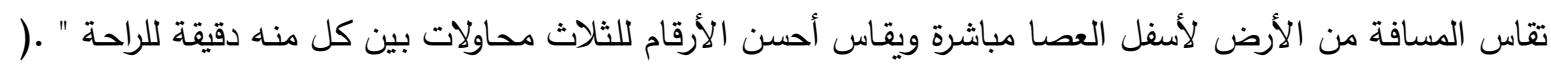

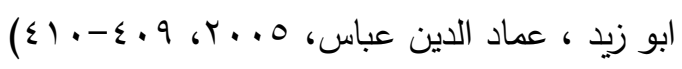


علاقة بعض القدرات الحركية الخاصة بدقة أداء مهارة الضرب الساحق المواجه بالكرة الطائرة

\section{الملحق (r)}

" اختبار دقة مهارة الضرب الساحق المستقيم (القطري)

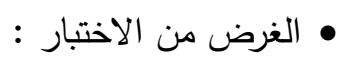

قياس دقة مهارة الضرب الساحق المستقيم في المثلث الداخلي من ملعب المنافس •

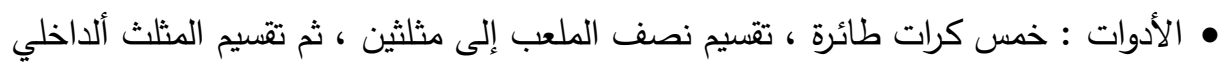

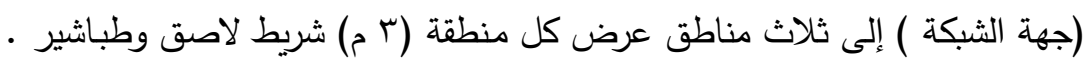

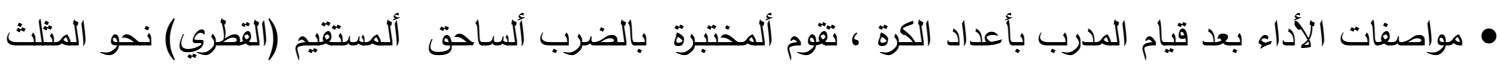

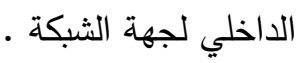

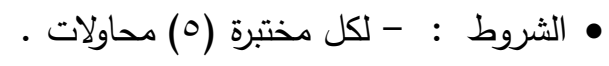
- يلزم ان يكون الأعداد جيداً في كل محاولة . - - تحتسب الدرجات على وفق مكان سقوط الكرة وكما يأتي : أ- في المنطقة الأولى (ب) درجات . ب- في المنطقة الثانية (1) درجة الاول (1) درجات

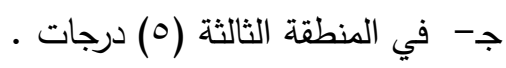
د - خارج هذه المناطق يحصل ألمختبر على (صغر) . • التسجيل : تسجل الدرجات التي تحصل عليها من المحاولات الخمس أي ان الدرجة ألنهائية لهذا الاختبار هي

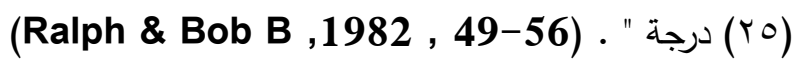

(ץ) ألملحق (r)

أسماء المتخصصين الذين وزعت عليهم استمارات الاستبيان لتصديد متغيرات ألاراسة

\begin{tabular}{|c|c|c|c|c|c|c|c|}
\hline \multicolumn{3}{|c|}{ طبيعة الاستشارة * } & \multirow{2}{*}{ عنوان الوظيفة } & \multirow{2}{*}{ الاختصاص ألاقيق } & \multirow{2}{*}{ أل ألعبمي } & \multirow{2}{*}{ أسـماء ألمحكمين } & \multirow{2}{*}{ ت } \\
\hline$r$ & r & 1 & & & & & \\
\hline$x$ & $x$ & $x$ & جامعة الموصل & اختبارات وقياس & أ. & ثيلام يونس علاوي & .1 \\
\hline$x$ & $x$ & $x$ & جامعة الموصل & طرق تدريس /الكرة الطائرة & د. أ & ليث محمد داؤد ألبنا &.$r$ \\
\hline$x$ & $x$ & $x$ & جامعة ألموصل & تعلم حركي / كرة القدم & أ أ د & نوفل فاضل رشيد &.$r$ \\
\hline$x$ & $x$ & $x$ & جامعة ألموصل & تعلم حركي/ كرة الطائرة & أ.م .د & خالد عبد ألمجيد ألخطيب &.$\varepsilon$ \\
\hline$x$ & $x$ & $x$ & جامعة ألموصل & تعلم حركي/ الكرة الطائرة & 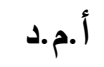 & احمد حامد السويدي & .0 \\
\hline$x$ & $x$ & $x$ & جامعة ألموصل & تعلم حركي / الكرة الطائرة & 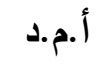 & خالد محمد داؤد & .7 \\
\hline$x$ & X & 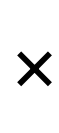 & تربية الحمدانية & مدرب نادي قره قوش /الكرة & م.م & السيد سعد بهنان بردى & $\cdot v$ \\
\hline
\end{tabular}

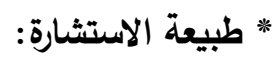

ا ـ تحديد القدرات الحركية.

r. ت تحديد أهم اختبارات القدرات الحركية.

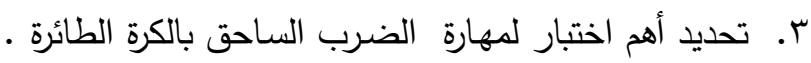

